ional Bureau of Standards

Library, N.W. Blds

OCT 2 j 1965

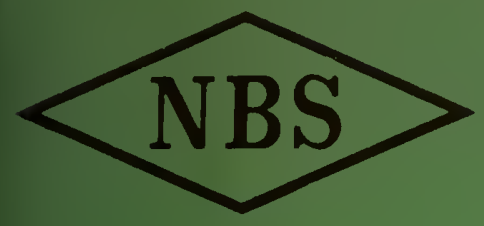

Eechnical Note

no. 324

\title{
INTERFERENCE PREDICTIONS FOR THE INSTRUMENT LANDING SYSTEM
}

By

G. D. GIERHART AND M. E. JOHNSON

U. S. DEPARTMENT OF COMMERCE NATIONAL BUREAU OF STANDARDS 


\section{THE NATIONAL BUREAU OF STANDARDS}

The National Bureau of Standards is a principal focal point in the Federal Government for assuring maximum application of the physical and engineering sciences to the advancement of technology in industry and commerce. Its responsibilities include development and maintenance of the national standards of measurement, and the provisions of means for making measurements consistent with those standards; determination of physical constants and properties of materials; development of methods for testing materials, mechanisms, and structures, and making such tests as may be necessary, particularly for government agencies; cooperation in the establishment of standard practices for incorporation in codes and specifications; advisory service to government agencies on scientific and technical problems; invention and development of devices to serve special needs of the Government; assistance to industry, business, and consumers in the development and acceptance of commercial standards and simplified trade practice recommendations; administration of programs in cooperation with United States business groups and standards organizations for the development of international standards of practice; and maintenance of a clearinghouse for the collection and dissemination of scientific, technical, and engineering information. The scope of the Bureau's activities is suggested in the following listing of its four Institutes and their organizational units.

Institute for Basic Standards. Applied Mathematics. Electricity. Metrology. Mechanics. Heat. Atomic Physics. Physical Chemistry. Laboratory Astrophysics.* Radiation Physics. Radio Standards Laboratory:* Radio Standards Physics; Radio Standards Engineering. Office of Standard Reference Data.

Institute for Materials Research. Analytical Chemistry. Polymers. Metallurgy. Inorganic Materials. Reactor Radiations. Cryogenics.* Materials Evaluation Laboratory. Office of Standard Reference Materials.

Institute for Applied Technology. Building Research. Information Technology. Performance Test Development. Electronic Instrumentation. Textile and Apparel Technology Center. Technical Analysis. Office of Weights and Measures. Office of Engineering Standards. Office of Invention and Innovation. Office of Technical Resources. Clearinghouse for Federal Scientific and Technical Information.**

Central Radio Propagation Laboratory.* Ionospheric Telecommunications. Tropospheric Telecommunications. Space Environment Forecasting. Aeronomy.

* Located at Boulder, Colorado 80301.

** Located at 5285 Port Royal Road, Springfield, Virginia 22171. 


\title{
NATIONAL BUREAU OF STANDARDS \\ Eechnical Note. 324 \\ ISSUED September, 1965
}

\section{INTERFERENCE PREDICTIONS FOR THE INSTRUMENT LANDING SYSTEM}

\author{
By
}

G. D. Gierhart and M. E. Johnson

Central Radio Propagation Laboratory

National Bureau of Standards

Boulder, Colorado

NBS Technical Notes are designed to supplement the Bureau's regular publications program. They provide a means for making available scientific data that are of transient or limited interest. Technical Notes may be listed or referred to in the open literature. 


\section{NOTICE}

This report has been prepared by the National Bureau of Standards for the Systems Research and Development Service, Federal Aviation Agency, under Contract No. FA-64-WAI-69, and has been published as a SRDS contractor report numbered RD-65-39. The contents of this report reflect the views of NBS, which is responsible for the facts and the accuracy of the data presented herein, and do not necessarily reflect the official views or policy of the FAA. This report does not constitute a standard, specification, or regulation. 
TABIE OF CONTENTS

Page No.

ABSTRACT

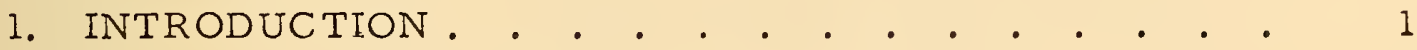

2. SYSTEM PARAMETERS . . . . . . . . . . 3

3. TRANSMISSION LOSS CALCULATIONS . . . . . . 7

4. INTERFERENCE BETWEEN TWO STATIONS . . . . 12

5. RESULTS OF THE STUDY . . . . . . . . . . . 14

5.1 Service Limitations Due to Co-Channel

Interference . . . . . . . . . . . 14

5. 2 Service Limitations Due to Adjacent-

Channel Interference . . . . . . . . 19

APPENDIX A. PROPAGATION MODELS . . . . . 24

A.1 Desired Station ILS Model . . . . . . . 31

A. 2 Undesired Station ILS Model . . . . . . 32

A. 3 Undesired Station VOR Model . . . . . 33

APPENDIX B. COMPUTATION TECHNIQUES • . . 35

B. 1 Interference Prediction Program . . . . 35

REFERENCES . . . . . . . . . . . . . . 41 


\section{LIST OF FIGURES}

Figure No. Title

Page No.

1 8-Loop Array Antenna Pattern

4

$2 \quad$ V-Ring Array Antenna Pattern

3 Cumulative Distributions of Aircraft Antenna Gain Ratios

4 Sketch Showing Relative Positions of Aircraft and of Navigational Aids over a Smooth Earth

5 Co-Channel ILS Interference; 6,250 feet

6 Co-Channel ILS Interference; 12,000 feet

7 Co-Channel ILS Interference; 18,000 feet

11 Geometry for Ray Interference within the Radio Horizon

12 Flow Diagram for Interference Prediction Program

\section{LIST OF TABLES}

Table No. Title

Page No.

1 Characteristics of ILS Localizers

2 VOR System Parameters

3 Co-Channel Station Combination Factor, C 


\section{A BSTRACT}

Co-channel and adjacent-channel interference predictions for the Instrument Landing System are presented in this report. Information on the varlous types of ground facilities involved is given first. Propagation mechanisms applicable to the 108 to $112 \mathrm{Mc} / \mathrm{s}$ frequency range are discussed second together with the calculation of transmission loss and its variability. Third, the statistical treatment of interference problems is explained. Finally; the results of the study are presented as curves of normalized desired-to-undesired signal strength ratios versus distance from the desired station. Aircraft altitudes of 1,000 , $6,250,12,000$, and 18,000 feet along with station separations ranging from 20 to 330 nautical miles were considered.

Detailed procedures, mathematical formulas, and computer programs used are discussed in the Appendices.

\section{KEY WORDS}

Instrument Landing System

Interference Predictions

Propagation 



\title{
INTERFERENCE PREDICTIONS FOR THE \\ INSTRUMENT LANDING SYSTEM
}

\author{
by \\ G. D. Gierhart and M. E. Johnson
}

\section{Introduction}

Increasing air traffic density together with fast, high-flying jets have made the use of reliable air navigation aids more important than ever before. In expanding the present complex of navigation aids to meet future demands, consideration must be given to potential interference between facilities operating on the same or on adjacent channels. The amount of interference is a function of the desired-to-undesired signal ratio at the aircraft antenna terminals; as both signals vary with time and aircraft location, the ratio varies as well, and the interference becomes dependent on time and location. Because of the nature of radio wave propagation in the frequency ranges used, the variations of the received signals and of the interference ratios are best described statistically. The large number of possible conditions dictates the use of a digital computer with programs that take into account all variables as well as the fixed equipment parameters.

The air navigation aid treated in this report is the Instrument Landing System (ILS). This system includes a runway localizer, a glide path, and marker beacons. However, in this study only the localizer is considered, since it is most susceptible to co-channel and adjacent-channel interference. The ILS localizer operates in the 108 to $112 \mathrm{Mc} / \mathrm{s}$ frequency range and shares this range with the VHF Omnirange 
(VOR) in such a way that VOR facilities have to be considered as the source of adjacent-channel interference.

At very high frequencies in the 30-300 Mc/s range (VHF), propagation of radio frequency energy is affected by the lower atmosphere (the troposphere), specifically by variations in the refractive index of the atmosphere. The terrain along and in the vicinity of the great circle path between transmitter and receiver also plays an important part.

Within the last decade a number of methods and procedures have been developed to calculate field strength and its variability at VHF. In the work discussed here procedures were followed which have been used by the Central Radio Propagation Laboratory to predict in a statistical manner the effect of terrain and atmosphere on the variability of field strength and on the performance of radio systems [Rice, Longley, Norton, and Barsis, 1965]. It is also convenient to use the concept of transmission loss [Norton, 1953 and 1959], which is the ratio of power radiated to the power that would be available at the receiving antenna terminals if there were no circuit losses other than those associated with the radiation resistance of the receiving antenna. It is used under the assumption that losses in the antenna circuits can be neglected, and it is usually expressed in decibels. Methods used for its calculation as a function of path length, terminal heights, and carrier frequency are discussed in Section 3. Computation techniques are discussed in Appendix B.

After some initial calculations, parameters for the ILS localizer and the VOR were assembled into a computer program which yields normalized signal-to-interference ratios for given probability-ofservice values as a function of aircraft location in relation to the desired and the undesired ground stations. The normalization involves the assumption that both the power and antenna gain associated with the desired and undesired station are the same. 
Results in the form of curves showing these ratios for both cochannel and adjacent-channel cases were obtained. Section 5 contains the information required to interpret the normalized curves in terms of parameters associated with three types of ILS ground equipment.

\section{System Parameters}

System parameters are based on several types of ILS ground equipment, a standard VOR ground installation, and passenger-jet aircraft antennas. Characteristics of three ILS localizers are listed in Table 1. Other equipment exists, but consideration of these three is sufficient for practical purposes.

TABLE 1

Characteristics of ILS Localizers

$\begin{array}{lcccr} & \text { Standard } & \text { Directional } & \text { Low Cost } \\ \text { Carrier Power* } & +20 \mathrm{dBW} & +20 \mathrm{dBW} & +10 \mathrm{dBW} \\ \text { Array Type } & 8-\text { Loop } & \text { V-Ring } & \text { V-Ring } \\ \text { Antenna Gain* } & +4 \mathrm{~dB} & +12 \mathrm{~dB} & +12 \mathrm{~dB} \\ \text { Array Height } & 5.5 \mathrm{ft} & 7.5 \mathrm{ft} & 7.5 \mathrm{ft}\end{array}$

In Table 1 carrier power refers to the carrier power delivered to the terminals of the carrier antenna, and antenna gain refers to the main lobe free space gain of the carrier antenna with reference to an isotropic radiator. Figures 1 and 2 show relative gain as a function of azimuth angle for the carrier portion of the 8-Loop [Civil Aeronautics Administration, 1957] and V-Ring arrays, respectively.

*See text. 
FREE SPACE GAIN FOR THE LOCALIZER CARRIER ANTENNA IN THE AZIMUTH

PLANE IS PLOTTED IN DECIBELS RELATIVE TO THE MAIN LOBE MAXIMUM.

THE GAIN OF THE MAIN LOBE MAXIMUM RELATIVE TO AN ISOTROPIC RADIATOR IS 4 DECIBELS.

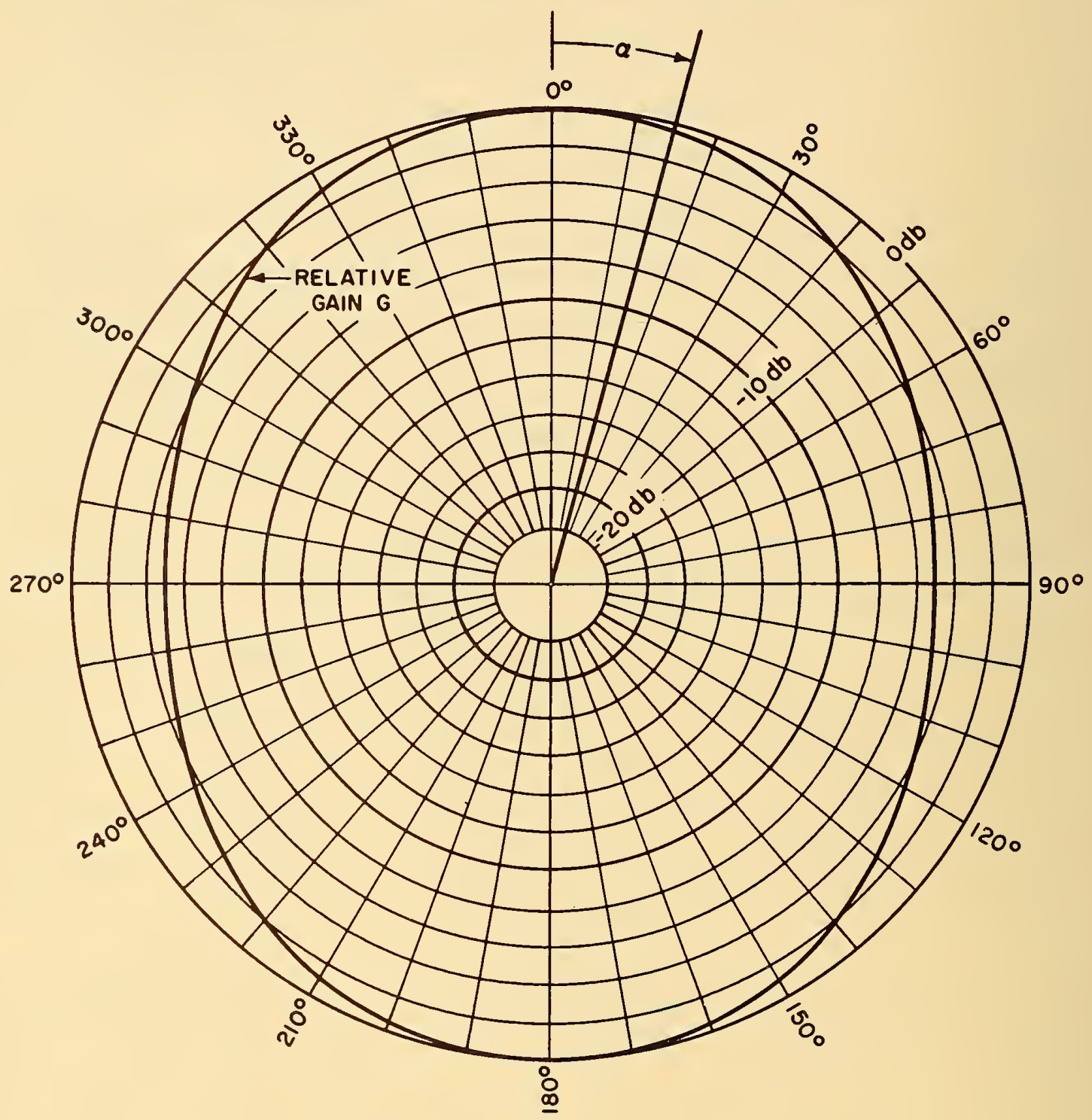

Figure 1. 8-Loop Array Antenna Pattern 
FREE SPACE GAIN FOR THE LOCALIZER CARRIER ANTENNA IN THE AZIMUTH PLANE IS PLOTTED IN DECIBELS RELATIVE TO THE MAIN LOBE MAXIMUM.

THE GAIN OF THE MAIN LOBE MAXIMUM RELATIVE TO

AN ISOTROPIC RADIATOR IS 12 DECIBELS.

VALUES PLOTTED ARE FOR A V-RING ARRAY (TYPE FA-5549X) WITH

A TYPE III ELEMENT SPACING AND CURRENT DISTRIBUTION.

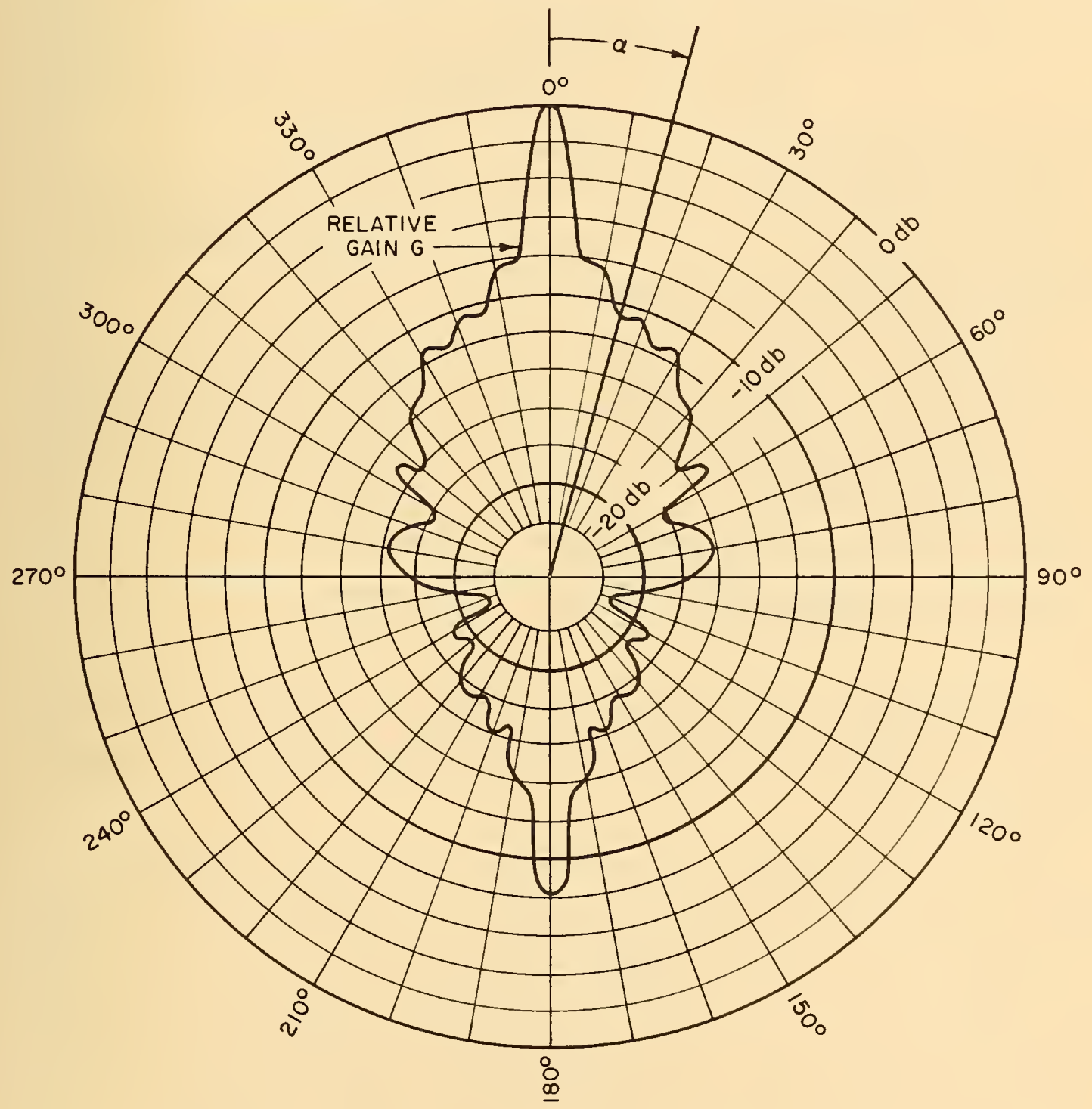

Figure 2. V-Ring Array Antenna Pattern 
Both the ILS localizer and the VOR use horizontally polarized antennas and were assumed to be operating at $110 \mathrm{Mc} / \mathrm{s}$. Other parameters used for the VOR are listed in Table 2 .

\section{TABLE 2}

VOR System Parameters

Carrier Power Delivered to Antenna

Ground Antenna Type

Maximum Antenna Gain Relative to

Isotropic Antenna

Free Space Horizontal Pattern

Free Space Vertical Pattern

Counterpoise Diameter

Antenna Height Above Counterpoise

Counterpoise Height Above Ground
$20 \mathrm{dBW}$

4-Loop Array (located above counterpoise)

2. $15 \mathrm{~dB}$

Approximately Circular Approximately Like Dipole

52 feet

4 feet

12 feet

Transmission line loss associated with the airborne terminal was considered to affect both the desired and the undesired signals equally and was neglected.

Aircraft antenna gain statistics were obtained from modeling study data based on an E-cavity type VOR antenna in the vertical stabilizer of passenger type jet aircraft [Convair, 1959; Commercial Jetstar, 1959]. Only the forward $\pm 20^{\circ}$ of azimuth were considered in obtaining statistic's for gain toward the desired station, but two sets of statistics were developed for gain in the direction of the undesired station. One set considered only the rear $\pm 20^{\circ}$ of azimuth and the other considered all azimuth angles as equally likely. From these statistics a single distribution was established for the ratio of antenna power gain in the direction of desired station to that in the direction of the undesired 
station. This ratio, expressed in decibels, is denoted by the symbol $R_{A}$ and the cumulative distribution, $R_{A}(p)$, used to account for air craft antenna gain is shown in figure 3. Also shown in figure 3 are two additional cumulative distributions of $R_{A}$ that resulted from the above mentioned analysis and were used as a guide to establish the $\mathrm{R}_{A}$ distribution used in the calculations.

\section{Transmission Loss Calculations}

Figure 4 shows a typical configuration of an aircraft (representing the receiving terminal), a desired navigational transmitting facility, and an undesired navigational transmitting facility. All three are aligned along a great circle path, and for simplicity assumed to be above a smooth surface. In the example drawn, the aircraft is within the radio horizon of the desired facility, but beyond the radio horizon of the interfering station. The distances along the great circle path from a point vertically below the aircraft to the desired and the undesired station are denoted by $d_{D}$ and $d_{U}$, respectively. The aircraft is at a height $h_{2}$ above the terrain. The angle $\theta$ between the horizon rays from the aircraft and the interfering station is an important parameter in the calculation of transmission loss for beyond-the-horizon paths [Norton, Rice, and Vogler, 1955]. For the assumption of a smooth spherical earth, $\theta$ is also the distance between radio horizons expressed in angular measure, and it is therefore called the "angular distance," as indicated on figure 4. As is customary in the analysis of tropospheric propagation paths, first order allowance for the refractive effects of the atmosphere was made by assuming an earth radius $4 / 3$ times the actual radius. This permits radio rays to be drawn as straight lines, and simplifies the determination of geometric parameters.

Transmission loss calculations were accomplished by (a) calculating a reference value of basic transmission loss, (b) calculating a 


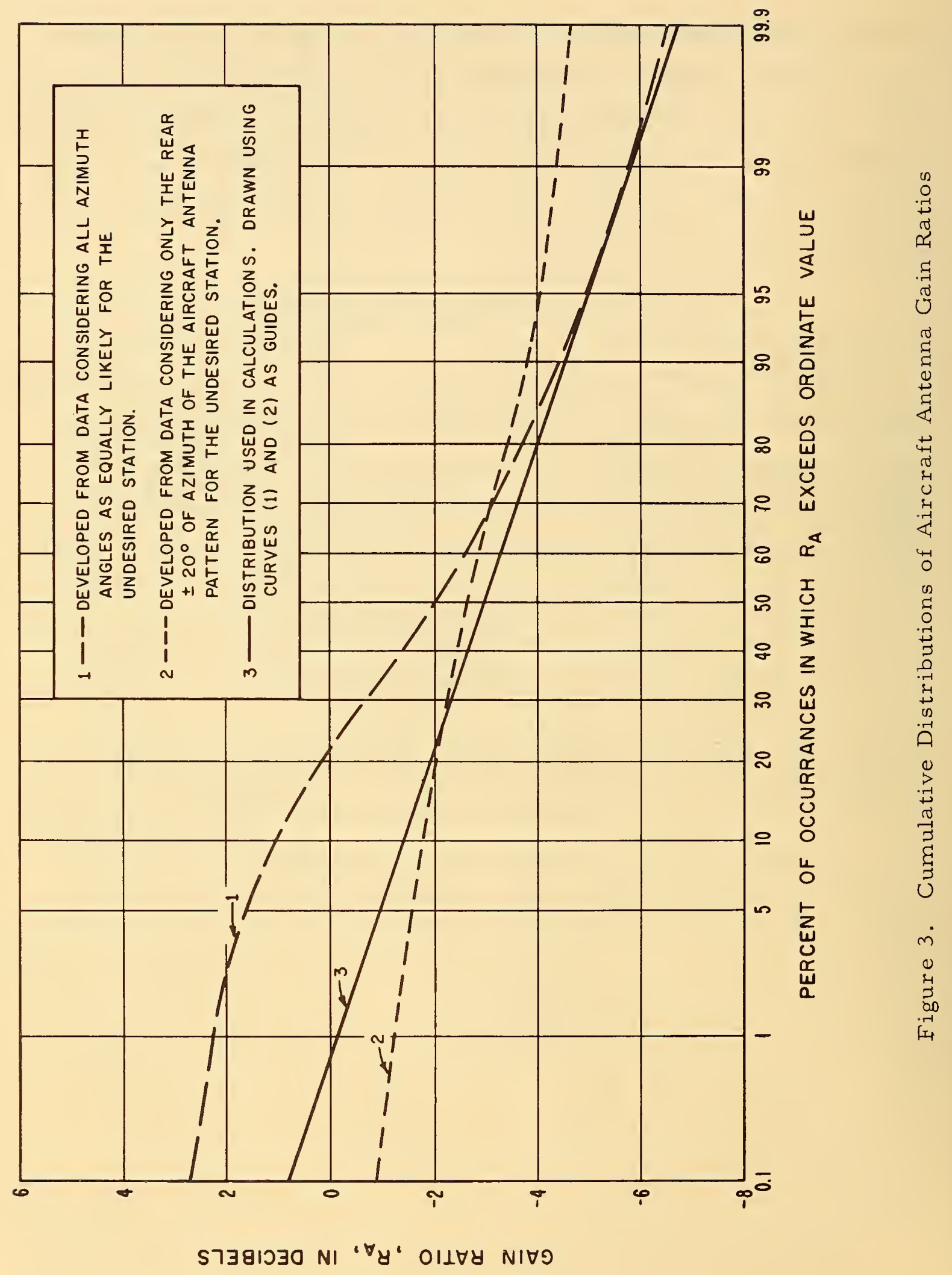




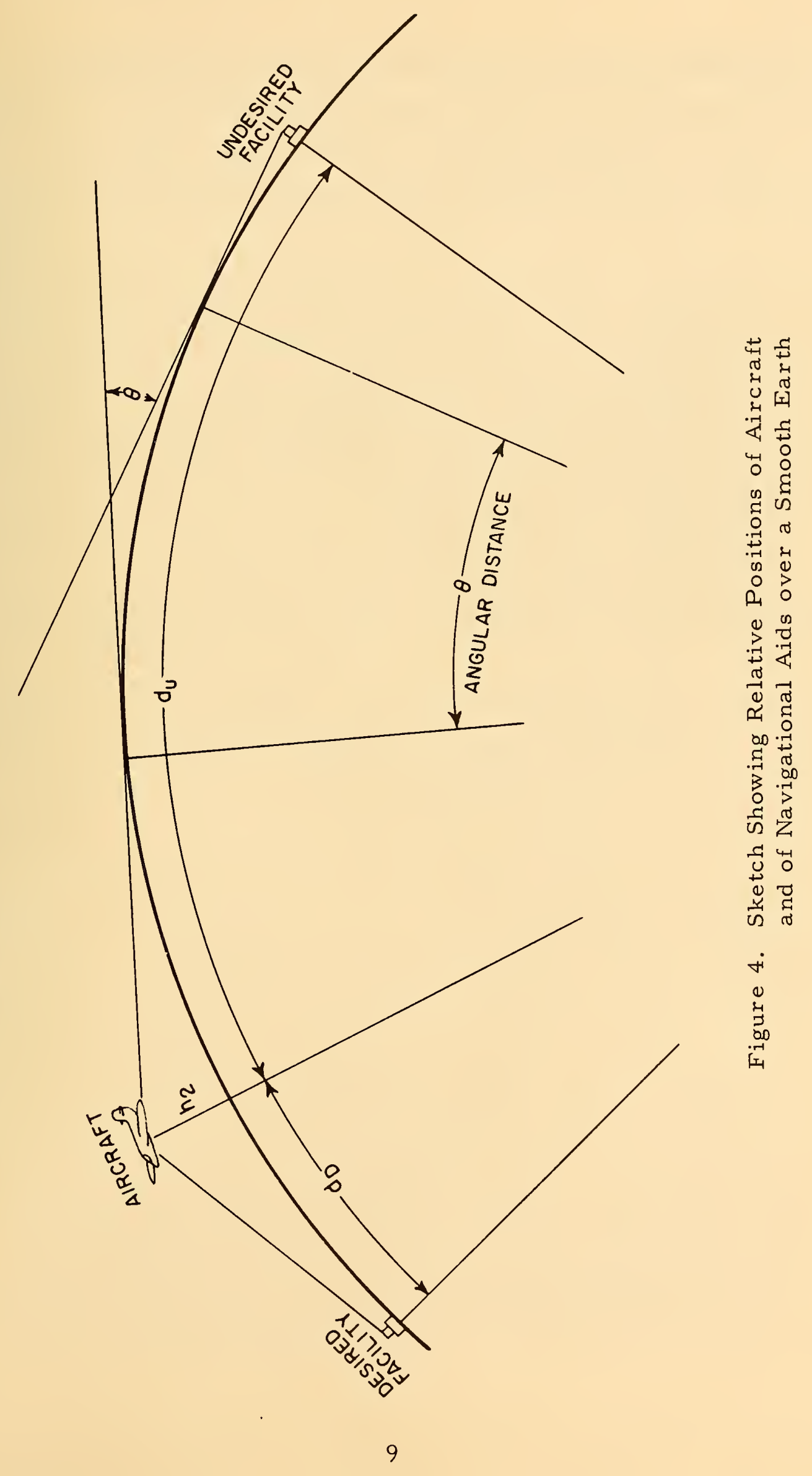


cumulative distribution for long-term variations, (c) calculating a cumulative distribution for short-term variations, and (d) calculating the cumulative distribution of transmission loss by combining the results of previous calculations. More detail on the se four steps follows:

(a) A reference value of basic transmission loss was calculated in accordance with methods given by Rice, et al. [1965]. This reference value, as explained by Norton, et al. [1955], is the median of all hourly medians within "Time Block 2, " representing the hours 1:00 p.m. to $6: 00 \mathrm{p} . \mathrm{m}$., November through April. In calculating "basic transmission loss" the antennas are considered to be isotropic with unity power or voltage gain in all directions. Actual antenna characteristics are brought in later on when converting from basic transmission loss to transmission loss. Within the radio horizon, basic transmission loss was calculated using geometric optics methods, including interference between the direct and the ground-reflected ray. For the desired ILS localizer and VOR propagation models, specular reflection was assumed with reflection coefficients equal to -0.9 . Because of the irregular nature of the terrain (buildings, etc. included) surrounding the undesired ILS stations, specular reflection was considered less dominating, and a combination of specular and diffused reflection was assumed. The primary effect of this assumption was to lower transmission loss values associated with the undesired ILS relative to comparable values for the desired ILS. This is discussed further in Appendix A. Beyond the radio horizon, basic transmission loss was calculated using smooth-earth diffraction or forward scatter models, depending 
on the path distance involved. Calculations for both models, and the method of properly combining diffraction and scatter fields if they are of comparable magnitude, were based on procedures contained in a Technical Note by Rice, et al. [1965].

(b) Long-term variations in basic transmission loss were estimated for a continental temperate climate by means of the time variability function $V(p, d)$. This empirical function was calculated in accordance with methods given by Rice, et al. [1965]. It was used to determine the cumulative distribution with time of hourly median basic transmission loss values relative to the reference values calculated under (a) above for all hourly median basic transmission loss values during the year as functions of path length, angular distance, terminal height, and carrier frequency.

(c) In addition to the distributions of hourly medians representing long-term variations, short-term (usually within-the-hour) distributions of the received signal levels had to be estimated. Short-term variations in this particular application are princi pally due to two causes. One is the inherent short-term fluctuation of the tropospheric signal ascribed to phase interference of rays reflected from small layers or scattered from refractive index discontinuities, or to reflections from ground irregularities. The other is the pattern of the aircraft antenna: numerous small lobes cause gain changes with varying bearings which can be represented by a cumulative distribution of antenna gain with time as the aircraft moves through space. However, it was more efficient to neglect the effect of the aircraft antenna gain in the initial transmission loss calculations and include it in later calculations as the $R_{A}(p)$ distribution discussed in 
Section 2. Short-term fading was described by a cumulative distribution function $V_{F}(p, \theta)$ which is based on fading range data given by Janes [1955].

(d) To obtain the cumulative distribution of transmission loss the functions discussed in $a, b$, and $c$ above were combined. The mechanics of combining cumulative distributions is discussed in more detail in Appendix B.

The prediction of interference conditions requires a knowledge of the time distribution of transmission loss or field strength at many points in space; therefore, time variability calculations have to be performed for these points with distance from the desired and undesired station, aircraft height, spacing of desired and undesired ground facilities, carrier frequency, and antenna patterns as parameters.

It should be noted here that the one-hour period taken as the dividing line between long-term and short-term variations is somewhat arbitrary. It is convenient in view of the available empirical time variability functions.

\section{Interference Between Two Stations}

As shown by figure 4 , both the desired and the undesired signals arrive at the aircraft over propagation paths characterized by the distances $d_{D}$ and $d_{U}$, respectively, and by the aircraft height. The distances are measured along the great circle path. Both signals vary with time, and the distributions of signal levels were calculated in accordance with the procedures outlined in the preceding section. Then the ratio of desired to undesired signal exceeded for given percentageof-time values at a particular aircraft location was determined.

The ratio of desired-to-undesired signal can be expressed as the decibel difference of desired and undesired signal levels and was 
obtained from calculated transmission loss values and other system parameters. The distribution of this ratio will be denoted $D / U(p)$, where $\mathrm{p}$ is that percentage of time during which a given value of $\mathrm{D} / \mathrm{U}$ is exceeded. By virtue of the aircraft being in motion, time variations also include variations in space. As the actual time distribution of $\mathrm{D} / \mathrm{U}$ may vary from installation to installation because of terrain characteristics and other factors not taken into account in this analysis, the time availability $p$ may be interpreted as an expression of reliability for a typical installation. The concepts of "prediction uncertainty" and "service probability" in the sense defined by Barsis, et al. [1962] were not used explicitly. It should, however, be understood that there is an uncertainty associated with the $\mathrm{D} / \mathrm{U}$ predictions of this study and that this uncertainty will increase under conditions where the assumed propagation models become less valid.

As an example, $D / U(95)=10 \mathrm{~dB}$ means that for a typical installation the ratio of the desired-to-undesired signal is equal to or greater than $10 \mathrm{~dB}$ during $95 \%$ of the time. Values of $\mathrm{D} / \mathrm{U}(95)$ are associated with the variables used in the calculations. These include: (1) interference type (co- or adjacent-channel), (2) aircraft altitude, (3) station separation, and (4) aircraft distance from the desired station.

To obtain the time availability of the desired-to-undesired ratio at any point in space it was necessary to properly combine the cumulative distributions of (a) transmission loss from the desired station, (b) transmission loss from the undesired station, and (c) the antenna power gain ratios, $R_{A}(p)$. Actually the se calculations resulted in a cumulative distribution of a normalized D/U. The process for converting normalized $\mathrm{D} / \mathrm{U}$ to actual $\mathrm{D} / \mathrm{U}$ values is discussed in Section 5. 


\section{Results of the Study}

The results of this study are in the form of normalized prediction curves. These curves may be used to estimate the service limitations imposed on ILS installations by co-channel and adjacent-channel interference. Other limitations to service such as thermal or man-made noise at the receiver and self interference caused by reflections from airport structures or other aircraft were not considered in this study. In particular, an "acceptable" desired-to-undesired signal ratio does not imply that the desired signal is strong enough for operational use.

In this section and in Appendix B values of normalized $D / U(95)$ will be denoted by the symbol $N\{D / U(95)\}$. These normalized values were calculated for the condition when the two ground stations and the aircraft were aligned over the same great circle arc. This was mentioned previously in Section 3 and is implied by the inset in figures 5 through 10. However, $\mathrm{N}\{\mathrm{D} / \mathrm{U}(95)\}$ values can also be obtained for cases where the assumed alignment is not valid by properly interpreting the station separation shown on the curves. Regardless of the shortest distance between the ground stations, the station separation, S, shown on the curves should always be regarded as the algebraic sum of the distance from the aircraft to the desired station, $d_{D}$, and the distance from the aircraft to the undesired station, $d_{U}$; i.e., $S=d_{D}+d_{U}$.

\subsection{Service Limitations Due to Co-Channel Interference}

$\mathrm{N}\{\mathrm{D} / \mathrm{U}(95)\}$ curves for aircraft altitudes of $6,250,12,000$, and 18, 000 feet are shown in figures 5, 6, and 7, respectively. Desired values of $\mathrm{D} / \mathrm{U}(95)$ may be converted to values of $N\{\mathrm{D} / \mathrm{U}(95)\}$ which can be read from the curves by the following procedure.

(a) Determine the value of co-channel station combination factor, C, from Table 3, on page 18 . 


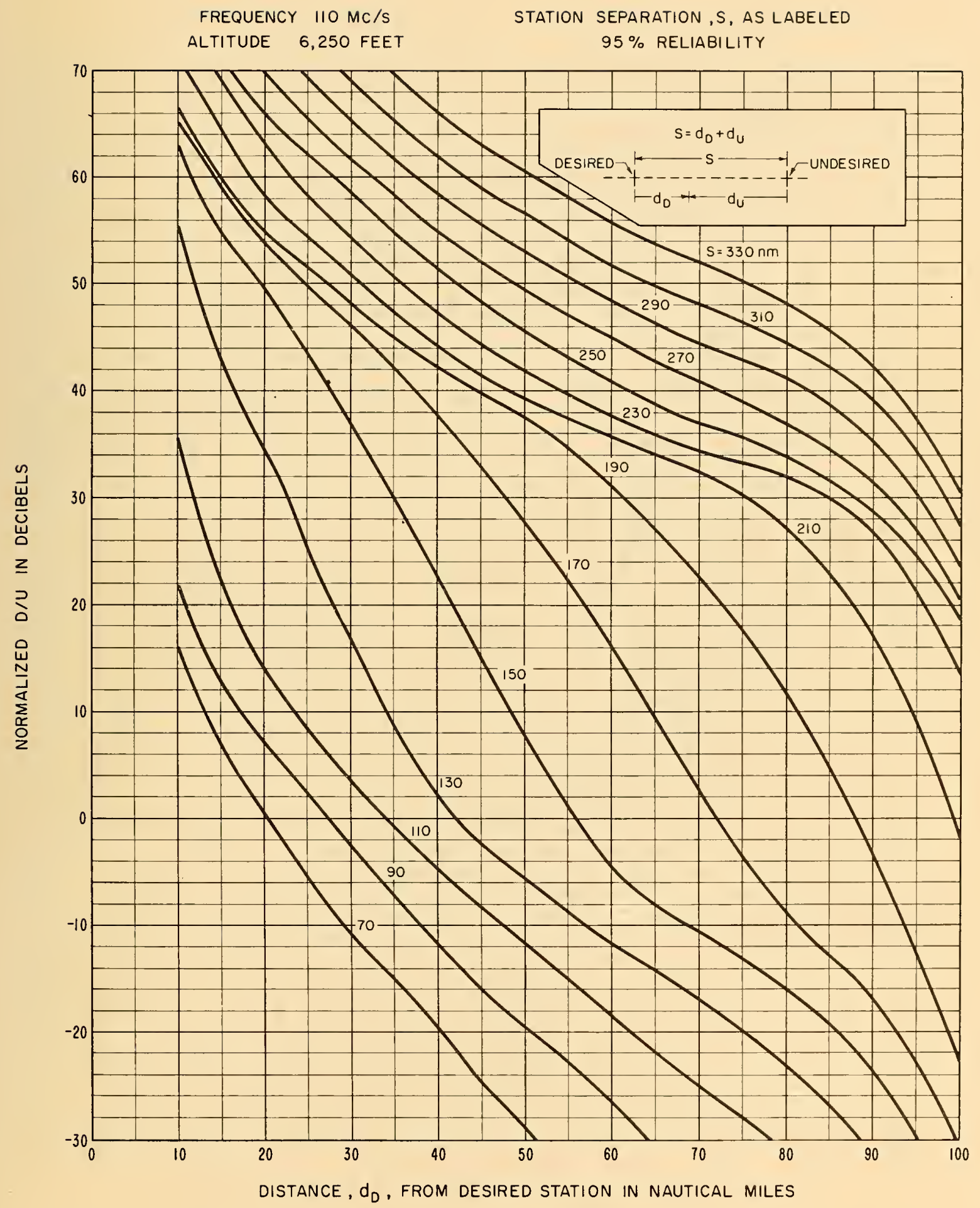

Figure 5. Co-Channel ILS Interference; 6, 250 feet 


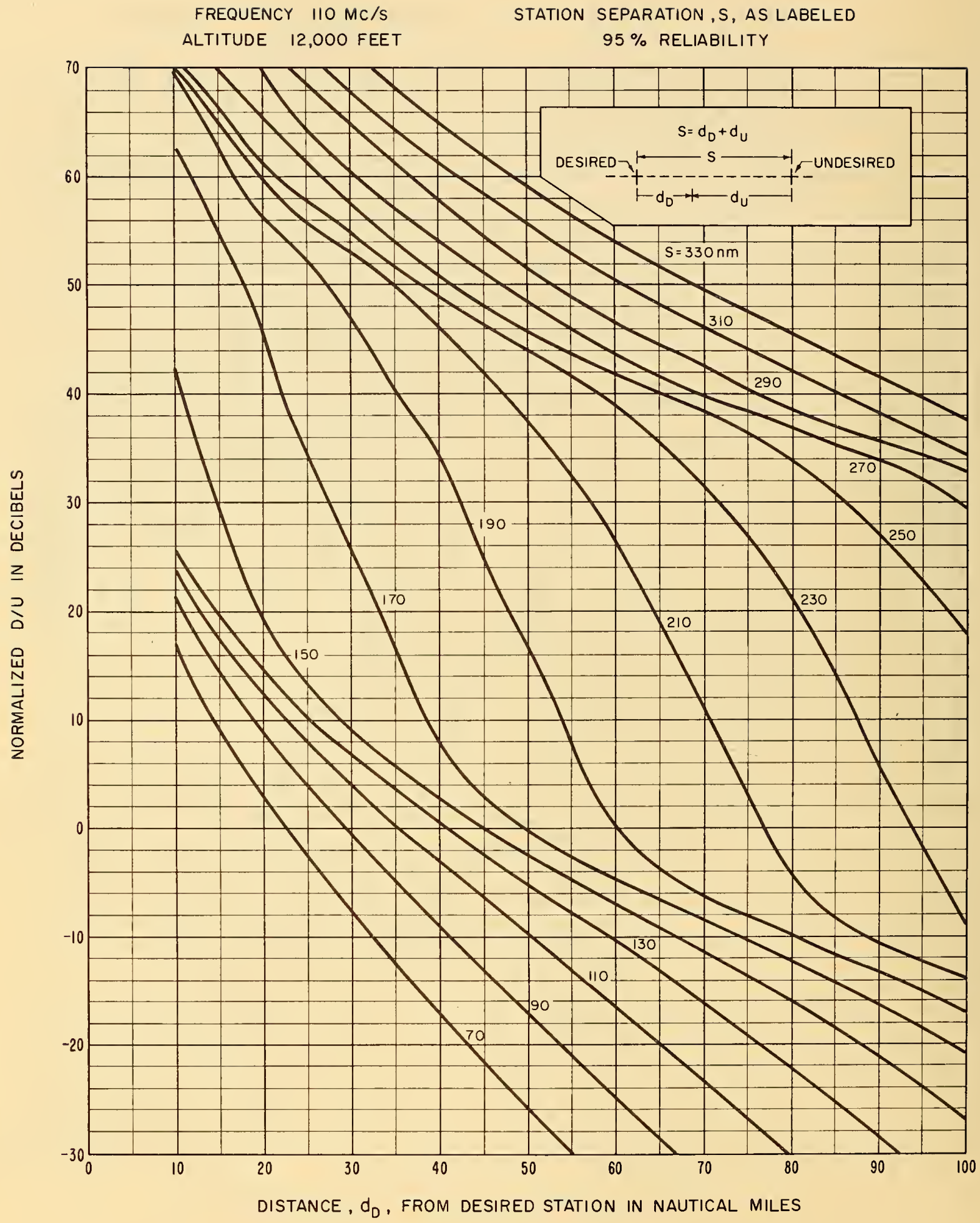

Figure 6. Co-Channel ILS Interference; 12, 000 feet 
FREQUENCY $110 \mathrm{Mc} / \mathrm{S}$

ALTITUDE 18,000 FEET
STATION SEPARATION, $S$, AS LABELED

$95 \%$ RELIABILITY

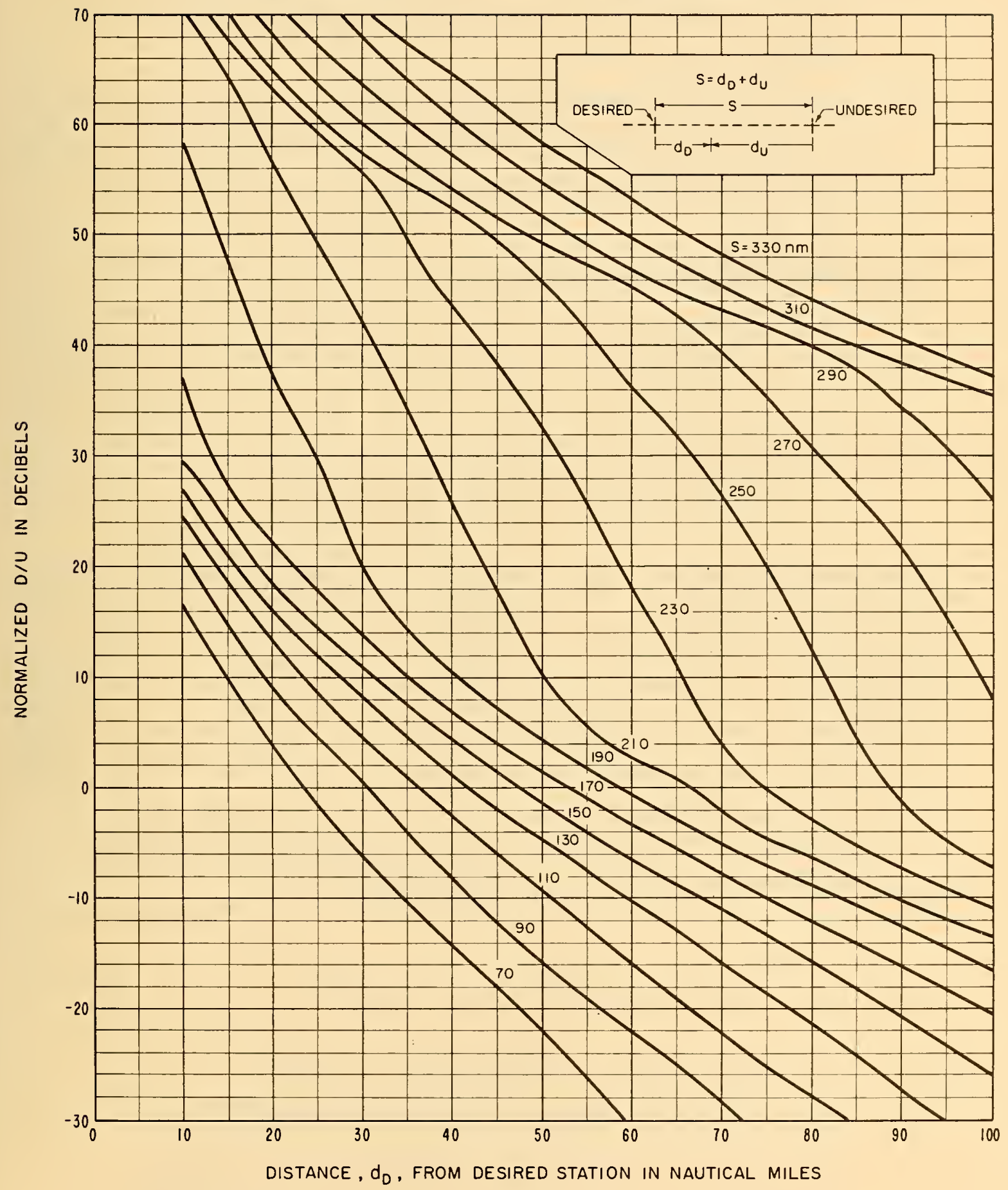

Figure 7. Co-Channel ILS Interference; 18, 000 feet 
(b) Determine the azimuth angle, $\alpha$, between main lobe maximum of localizer carrier antenna at the undesired station and the aircraft.

(c) Using $\alpha$ and the antenna pattern (figure 1 or 2) appropriate for the undesired station type, determine the gain factor, $G$, of the undesired localizer carrier antenna in the direction of the aircraft.

(d) Calculate $\mathrm{N}\{\mathrm{D} / \mathrm{U}(95)\}$ using

$$
\mathrm{N}\{\mathrm{D} / \mathrm{U}(95)\}=\mathrm{D} / \mathrm{U}(95)-\mathrm{C}+\mathrm{G}
$$

\section{TABLE 3}

Co-Channel Station Combination Factor, C

\begin{tabular}{|c|c|c|c|}
\hline \multirow[b]{2}{*}{ Desired Station Type } & \multicolumn{3}{|c|}{ Undesired Station Type } \\
\hline & $\underline{\text { Standard }}$ & Directional & Low Cost \\
\hline Standard & $0 \mathrm{~dB}$ & $-10.5 \mathrm{~dB}$ & $-0.5 \mathrm{~dB}$ \\
\hline Directional & $10.5 \mathrm{~dB}$ & $0 \mathrm{~dB}$ & $+10 \mathrm{~dB}$ \\
\hline Low Cost & $0.5 \mathrm{~dB}$ & $-10 d B$ & $0 \mathrm{~dB}$ \\
\hline
\end{tabular}

The values of $\mathrm{C}$ in Table 3 were calculated from information given in Table 1 by using the following equation:

$$
C=P_{D}-P_{U}+A_{D}-A_{U}+H_{D}-H_{U}
$$

where $P_{D}=$ desired station carrier power in $\mathrm{dBW}$,

$P_{U}=$ undesired station carrier power in dBW,

${ }_{D}=$ free space antenna gain referred to an isotropic radiator for the main lobe of the desired station localizer carrier antenna, 
$\mathrm{A}_{U}=$ antenna gain similar to $A_{D}$, but for undesired station, $\mathrm{H}_{\mathrm{D}}=$ height gain factor for desired station, $\mathrm{H}_{\mathrm{D}}=0 \mathrm{~dB}$ for array height of 5.5 feet (8-Loop). $\mathrm{H}_{\mathrm{D}}=2.5 \mathrm{~dB}$ for array height of 7.5 feet (V-Ring). $\mathrm{H}_{\mathrm{U}}=$ height gain factor similar to $\mathrm{H}_{\mathrm{D}}$, but for undesired station $\left(\mathrm{H}_{\mathrm{U}}=0 \mathrm{~dB}\right.$ for adjacent-channel calculations).

Values of $G$ read from figures 1 or 2 represent the gain of the undesired localizer carrier antenna in the direction of the aircraft relative to the gain of the same antenna in the direction of the main lobe maximum. Because of this, values of $G$ are always negative and $\mathrm{D} / \mathrm{U}(95)$ will have its worst (lowest) values for a particular pattern when $G$ is 0 .

5.2. Service Limitations Due to Adjacent-Channel Interference Adjacent-channel $N\{D / U(95)\}$ curves for aircraft altitudes of $1,000,6,250$, and 12,000 feet are shown in figures 8,9 , and 10 , respectively. Values of $\mathrm{D} / \mathrm{U}(95)$ may be converted to values of $\mathrm{N}\{\mathrm{D} / \mathrm{U}(95)\}$ which can be read from the curves by the following procedure:

(a) Determine the value of the adjacent-channel station combination factor, C, from Table 4.

(b) Calculate $\mathrm{N}\{\mathrm{D} / \mathrm{U}(95)\}$ using

$$
\mathrm{N}\{\mathrm{D} / \mathrm{U}(95)\}=\mathrm{D} / \mathrm{U}(95)-\mathrm{C}
$$

TABLE 4

Adjacent-Channel Station Combination Factor, C Desired Station Type

\begin{tabular}{lll}
\hline Standard & Directional & Low Cost \\
$1.85 \mathrm{~dB}$ & $12.35 \mathrm{~dB}$ & $2.35 \mathrm{~dB}$
\end{tabular}


FREQUENCY $110 \mathrm{MC} / \mathrm{S}$

ALTITUDE I,OOO FEET
STATION SEPARATION,S, AS LABELED

$95 \%$ RELIABILITY

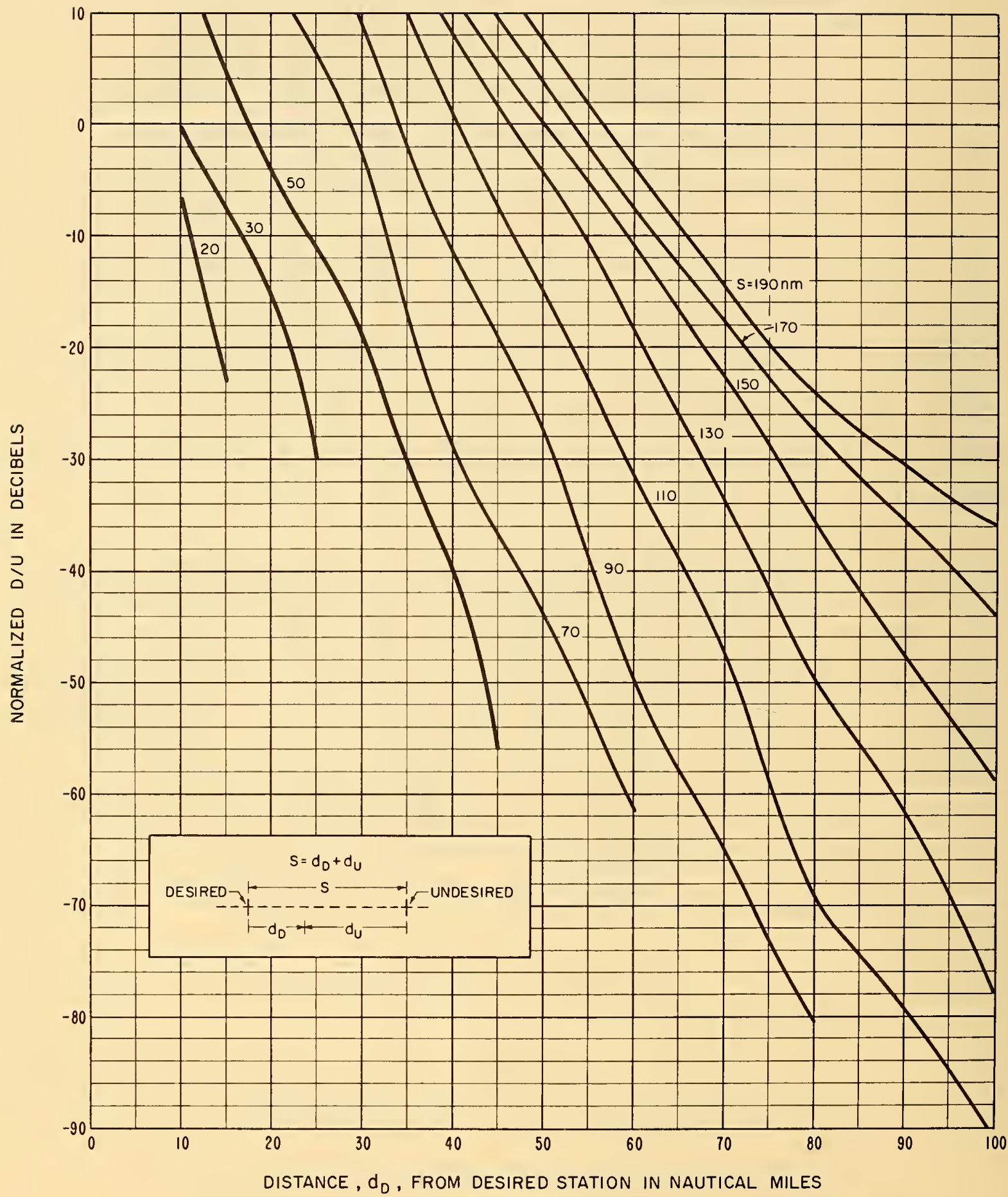

Figure 8. Adjacent-Channel ILS Interference; 1,000 feet 


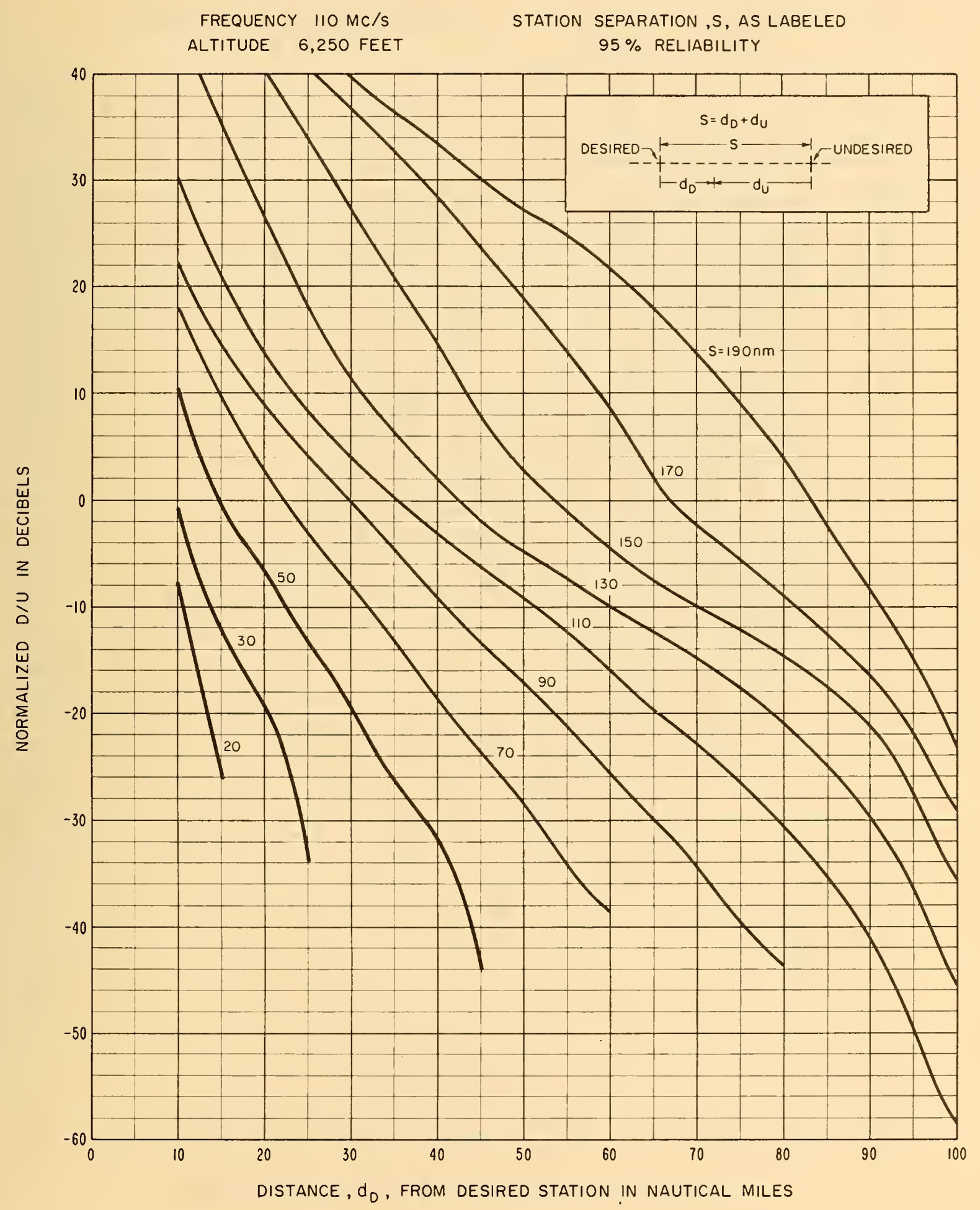

Figure 9. Adjacent-Channel ILS Interference; 6, 250 feet 
FREQUENCY $110 \mathrm{MC} / \mathrm{s}$

ALTITUDE 12,000 FEET
STATION SEPARATION ,S, AS LABELED

$95 \%$ RELIABILITY

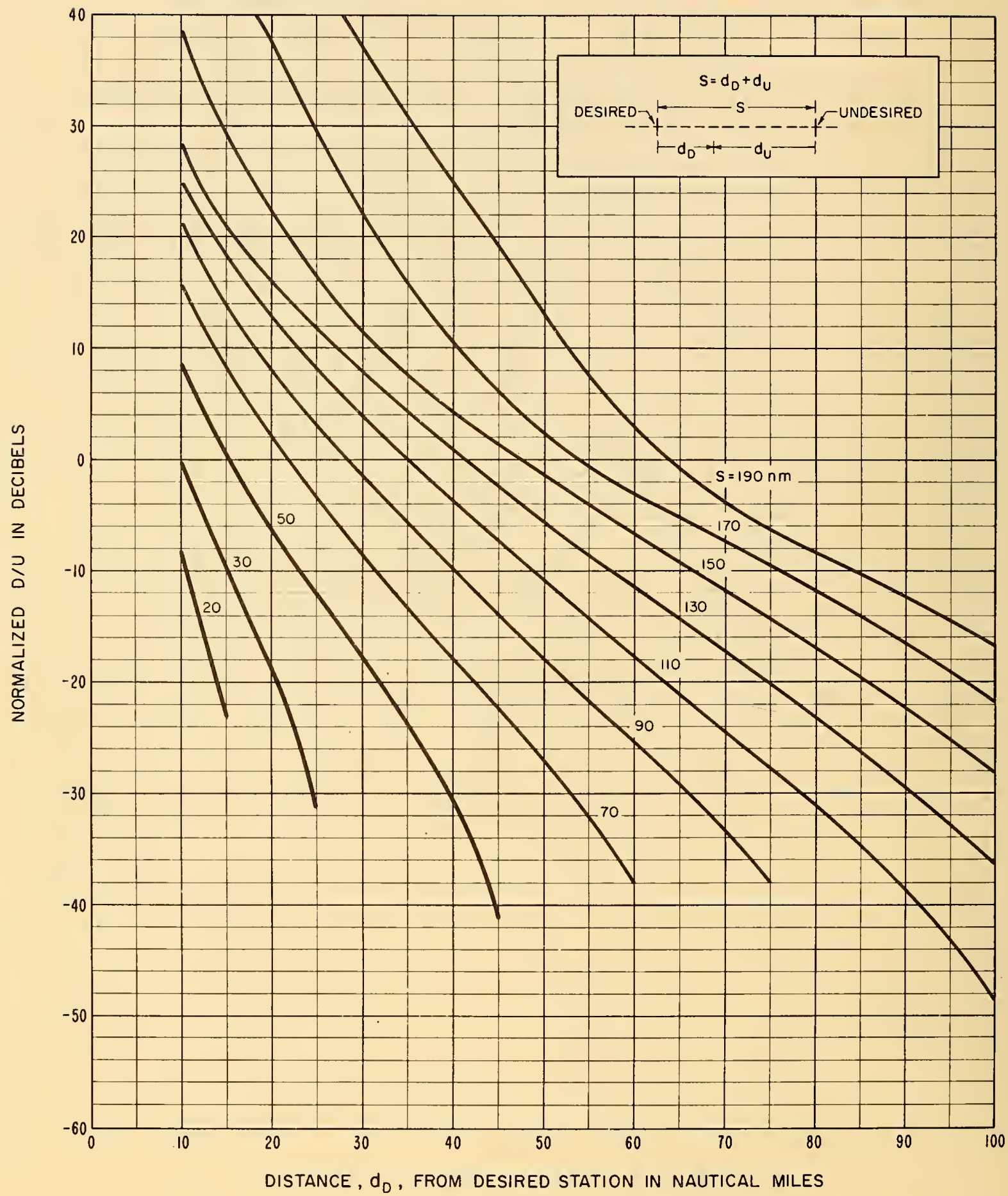

Figure 10. Adjacent-Channel ILS Interference; 12, 000 feet 
The values of $\mathrm{C}$ in Table 4 were calculated from information given in Tables 1 and 2 by using the equation given in Section 5.1. $\left(\mathrm{H}_{\mathrm{U}}=0 \mathrm{~dB}\right.$ for VOR. $)$

In the adjacent-channel case the calculation of $\mathrm{D} / \mathrm{U}(95)$ is somewhat simpler than in the co-channel case. This is because the adjacentchannel undesired station is always a VOR and the VOR has an omnidirectional radiation pattern in the horizontal plane; thus no gain factor is required. 


\section{Propagation Models}

A smooth, spherical earth model was used to calculate transmission loss for the ILS and VOR system at $110 \mathrm{Mc} / \mathrm{s}$. A lineargradient atmosphere was assumed for the initial calculations, so that for a first approximation, radio rays could be considered to be straight lines above an earth having an effective radius $k$ times its actual value. In conformance with usual practice, the effective earth radius factor, $k$, was assumed to be $4 / 3$ for the "standard" atmosphere. Calculation methods are based on material contained in a Technical Note by Rice, et al. [1965].

It was found convenient to include only the gain of the transmitting antenna in the definition of transmission loss as used in the se calculations. Usually, the term "transmission loss" includes the antenna gains at both path terminals, whereas the term "basic transmission loss" excludes all antenna gains [Norton, 1953 and 1959]. In this study, an hourly median transmission loss, $L_{m}$, is defined to include the freespace gain of the transmitting antenna as a function of the elevation angle as well as the effect of reflections from the counterpoise (VOR only) and from the ground.

Within the radio horizon, values of the hourly median transmission loss, $L_{m}$, were calculated using geometrical optics methods [Kirby, Herbstreit, and Norton, 1952]. These methods take into account the interference between the direct and the ground-reflected ray. Figure 11 shows the geometry for this ray interference problem, and defines many of the symbols used in the analysis. Using this geometry, curves of $L_{m}$ versus distance were calculated for each assumed aircraft altitude. The following constants and relationships were used, with 
distances and angles measured in statute miles and radians, respectively:

a. . . 5280 statute miles $=4 / 3$ times the actual radius of the earth

$h_{1}$. . . height of the transmitting antenna above the reflecting surface

$\mathrm{h}_{2}$. . . aircraft altitude above the reflecting surface

$|R|$. . . magnitude of the reflection coefficient

c . . . phase angle of the reflection coefficient relative to $\pi$, and assumed to be zero

D. . . divergence factor

d. . . distance along the great circle path to a point on the reflecting surface below the aircraft

$\mathrm{r}_{\mathrm{O}^{*}} \cdot$. length of the direct ray path

$r_{1}+r_{2} \cdot$. length of the reflected ray path

$d_{1}$. . . distance from transmitting antenna to reflection point

$\mathrm{d}_{2}$. . . distance from aircraft to reflection point

$\psi$. . . grazing angle at reflection point

The first step was the determination of the grazing angle $\psi$. For a given value of $d$ the following equations were used:

$$
\begin{gathered}
\mathrm{d}=\mathrm{d}_{1}+\mathrm{d}_{2} \\
\mathrm{~h}_{1}^{\prime}=\mathrm{h}_{1}-\mathrm{d}_{1}^{2} / 2 \mathrm{a} \\
\mathrm{h}_{2}^{\prime}=\mathrm{h}_{2}-\mathrm{d}_{2}^{2} / 2 \mathrm{a} \\
\tan \psi=\mathrm{h}_{1}^{\prime} / \mathrm{d}_{1}=\mathrm{h}_{2}^{\prime} / \mathrm{d}_{2} .
\end{gathered}
$$

Equations (5), (6), and (7) are approximate relations. In order to utilize the electronic computer in solving the above expressions for 


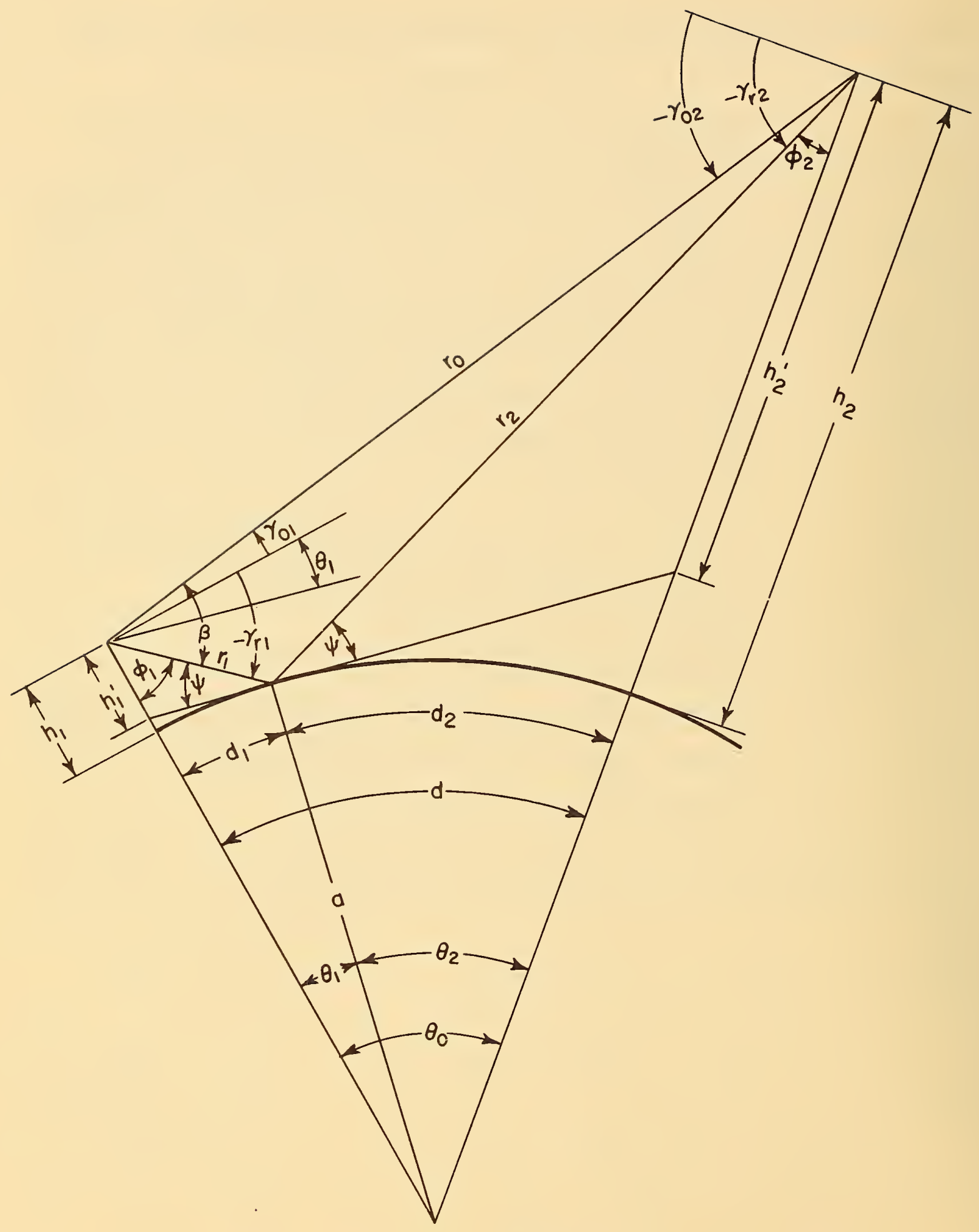

Figure 11. Geometry for Ray Interference within the Radio Horizon 
grazing angle, $\psi$, an iteration method was used, assuming for each d different values of $d_{1}$ until the equations were satisfied within the desired limits of accuracy, which was $\pm 10^{-6}$ miles. Final values for $\psi$ for each assumed total distance $d$ were then used in calculating various auxiliary angles and quantities to be used in ray-tracing and in the final calculation of the transmission loss $\mathrm{L}_{\mathrm{m}}$.

Using the previously calculated value of $\psi$ other geometrical parameters shown in figure 11 were calculated as follows:

$$
\begin{aligned}
& \sin \phi_{1}=(a \cos \psi) /\left(a+h_{1}\right) \\
& \sin \phi_{2}=(a \cos \psi) /\left(a+h_{2}\right) \\
& \theta_{1}=\pi / 2-\psi-\phi_{1} \\
& \theta_{2}=\pi / 2-\psi-\phi_{2} \\
& r_{2}=\left(a \sin \theta_{2}\right) /\left(\sin \phi_{2}\right) \\
& \theta_{0}=\theta_{1}+\theta_{2} \\
&\left.=\sqrt{\left(h_{1}\right.}-h_{2}\right)^{2}+4\left(a+h_{1}\right)\left(a+h_{2}\right)\left[\sin \left(\theta_{0} / 2\right)\right]^{2} \\
& r_{0} \\
& \sin \beta=\left[r_{2} \sin (\pi-2 \psi)\right] / r_{0} \\
& \gamma_{r 1}=-\left(\psi+\theta_{1}\right) \\
& \gamma_{01}=\beta-\psi-\theta_{1}
\end{aligned}
$$


The divergence factor $D$ was calculated using

$$
D=\frac{1}{\sqrt{1+\left(\frac{2 d_{1} d_{2}}{a d \tan \psi}\right)}}
$$

Voltage gains $g_{01}$ and $g_{r l}$ of the ground antenna relative to that of an isotropic radiator were calculated by:

$$
g_{01}=1.28 \cos \gamma_{01}
$$

and

$$
g_{r 1}=1.28 \cos \gamma_{r 1} \text {. }
$$

The phase angle $\Delta$, in radians, between the direct and reflected rays due only to the difference in ray length was calculated using

$$
\Delta=\frac{2.42 \mathrm{f}_{\mathrm{Mc}} \mathrm{h}_{1}^{\prime} \mathrm{h}_{2}^{\prime}}{\mathrm{d}}
$$

where $\mathrm{f}_{\mathrm{Mc}}=110 \mathrm{Mc} / \mathrm{s}$.

Then $L_{m}$ was calculated from the following formula:

$$
I_{m}=36.58+20 \log _{10} f_{M c}
$$

$+20 \log _{10} \mathrm{r}_{0}-10 \log _{10}\left\{\mathrm{~g}_{01}{ }^{2}+\left[\mathrm{D}|\mathrm{R}| \mathrm{g}_{\mathrm{r} 1}\right]^{2}-2 \mathrm{~g}_{01} \mathrm{~g}_{\mathrm{r} 1} \mathrm{D}|\mathrm{R}| \cos \Delta\right\}$

In the above equations distances and heights are measured in

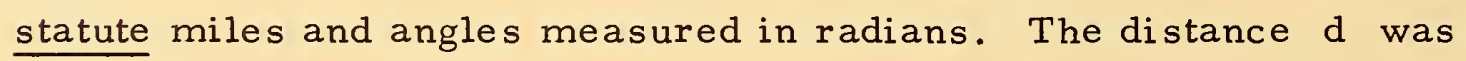
converted to nautical miles after $L_{m}$ was calculated. 
For large distances and low angles the linear gradient atmosphere predicts too much bending [Bean and Thayer, 1959]. To correct for this, a ray leaving the ground station antenna at the same angle, $\gamma_{01}$, as the direct ray (calculated using a linear gradient atmosphere) was traced through an exponential atmosphere until it reached the aircraft altitude. The great circle distance below the ray was then used in the final calculations instead of the distance d first assumed. The exponential atmosphere used corresponds to the reference atmosphere given by Rice, et al. [1965] with a surface refractivity of $\mathrm{N}_{\mathrm{S}}=301$. Calculations of transmission loss beyond the radio horizon were made by combining smooth-earth diffraction with tropospheric scatter. The short-cut method of Vogler [1961] was used for diffraction computations. Scatter computations and methods of combining the two mechanisms follow the work by Rice, et al. [1965] .

Calculations for the beyond-the-horizon case are based on the same exponential atmosphere used for within-the-horizon computations. The electrical constants of the ground assumed for calculations of the diffracted wave were a dielectric constant, $\epsilon=15$, and a conductivity value, $\sigma=5$ millimhos per meter. At the carrier frequency used, however, the effect of ground constants is small.

Finally, from a large number of computations both within and beyond the radio horizon, a set of curves was drawn for discrete aircraft altitudes showing the expected median transmission loss as a function of the great circle distance, d, (assuming the antenna gain of the ground station to correspond to a half-wave dipole). The construction of these curves involved a certain amount of blending in the vicinity of the radio horizon [Kerr, 1964].

Long-term variability, short-term fading, and the effective gain variations of the airborne antenna were treated statistically. Longterm variability was described by the time availability function $V(p, d)$. 
Equations and curves given by Rice, et al. [1965] were used to calculate the $V(p, d)$ applicable to all hours of the year, for a continental temperate climate.

Short-term fading was described by a cumulative distribution function $V_{F}(p, \theta)$ which includes the summing of a constant vector and a Rayleigh-distributed vector. The angular distance, $\theta$, is defined to be the angle between horizon rays from the transmitter and receiver [Norton, Rice, and Vogler, 1955], and is defined on figure 4 of the main body of this report. An auxiliary distribution function $V_{F}^{\prime}(p, \theta)$ was developed using, 1) fading range data for $100 \mathrm{Mc} / \mathrm{s}$ from a paper by Janes [1955] to express fading range as a function of $\theta$, and 2) figure 6 and Table 1 from Norton, Vogler, Mansfield, and Short [1955] to specify a cumulative distribution, $V^{\prime}{ }_{F}(p, \theta)$, for the fading range given by a particular value of $\theta$. The distribution functions $\mathrm{V}_{F}(\mathrm{p}, \theta)$ and $V_{F}^{\prime}(p, \theta)$ are related by

$$
V_{F}(p, \theta)=V_{F}^{\prime}(p, \theta)-V_{F}^{\prime}(50, \theta)
$$

It was unnecessary to consider a different aircraft antenna gain for the direct and reflected rays because their arrival angles are nearly equal as would be more apparent if figure 11 was drawn to scale. This made calculations considerably simpler since the effect of aircraft antenna gain on $\mathrm{N}\{\mathrm{D} / \mathrm{U}(95)\}$ could be considered in transmission los calculations without including the above mentioned gain. The method involved is outlined in Appendix $B$ and uses the distribution $R_{A}(p)$ shown in figure 3.

Distributions of transmission loss values were calculated using the following equation:

$$
L(p, d)=L_{m}-\left[V(p, d) * V_{F}(p, \theta)\right]
$$


In this equation all terms except $L_{m}$ are cumulative distributions, so that the calculation of $L(p, d)$ required the use of a convolution process which is indicated by the operational symbol *, and will be further discussed in Appendix B. As previously implied, in calculating $L(p, d)$ an isotropic aircraft antenna was assumed. When the fading range was zero the effect of $V_{F}(p, \theta)$ could be neglected and $V_{F}(p, \theta)$ was dropped from equation (24).

In general the above discussion applies to all propagation models used in this study. However, more information is required to make the description of each model reasonably complete. Information relevant to particular models is contained in the remaining parts of this appendix.

\section{A. 1 Desired Station ILS Model}

The propagation model used for the desired ILS localizer carrier system is described accurately, but not completely in the first part of this appendix.

In the calculations, the ground antenna was assumed to be a single Alford loop 5.5 feet above ground. The total gain of the carrier antenna and the carrier power were not considered in the calculation of $\mathrm{N}\{\mathrm{D} / \mathrm{U}(95)\}$. These can be taken into account by the procedure given in Section 6 for converting $N\{D / U(95)\}$ to $D / U(95)$.

For this model the fading range values on which $V_{F}(p, \theta)$ was based were approximated by

$$
\begin{gathered}
0 \text { for } \theta<0 \\
1+12.4 \theta \mathrm{dB} \text { for } 0 \leq \theta \leq 1^{\circ} \\
13.4 \mathrm{~dB} \text { for } \theta \geq 1^{\circ} .
\end{gathered}
$$




\section{A. 2 Undesired Station ILS Mode1}

The propagation model used for the undesired ILS localizer carrier system was the same as that used for the desired ILS station with respect to assumptions made about the ground antenna and the methods used to calculate $L_{m}$ beyond the radio horizon. It differed in the method used to calculate $\mathrm{L}_{\mathrm{m}}$ within the radio horizon and the approximation used to describe fading range.

The within-the-horizon $L_{m}$ curves for the undesired ILS were developed by utilizing the $L_{m}$ curve used for the desired ILS along with a similar curve developed by essentially neglecting the ground reflections. Both curves were plotted on the same sheet with loss measured along the ordinate by a scale linear in decibels and distance from the station measured along the abscissa by a scale linear in nautical miles. The undesired ILS $L_{m}$ curve was then obtained by interpolating a smooth curve between the curves previously drawn such that the new curve merged with the desired ILS $L_{m}$ curve in the vicinity of the radio horizon and merged with the "free space" loss curve at about 10 nautical miles from the station. This procedure was used in order to estimate the effect of terrain roughness around the undesired ILS and to avoid making quantitative assumptions about the effect of terrain roughness on the specular reflection coefficient. It assumes that the specular reflection coefficient is -0.9 at maximum within-the horizon range (low grazing angle) and that as the range is decreased with fixed altitude (higher grazing angle) the effect of terrain roughness serves to reduce the absolute value of the specular reflection coefficient.

A random reflection coefficient of 0:3 [ McGavin and Maloney, 1959] was assumed to be associated with the rough terrain surrounding an undesired ILS. The effect of this reflection was accounted for by the short-term fading function $\mathrm{V}_{F}(\mathrm{p}, \theta)$. For this model the fading range 
values on which $V_{F}(p, \theta)$ was based, were

$$
\begin{gathered}
4.7 \mathrm{~dB} \text { for } \theta \leq 0^{\circ} \\
1+12.4 \theta \mathrm{dB} \text { for } 0 \leq \theta \leq 1^{\circ} \\
13.4 \mathrm{~dB} \text { for } \theta \geq 1^{\circ} .
\end{gathered}
$$

\section{A. 3 Undesired Station VOR Model}

The propagation model used for the undesired VOR localizer follows the description given at the beginning of this appendix except in the region where reflection from the counterpoise was considered. Remarks made concerning antenna assumptions in the discussion of the desired ILS model are applicable to the VOR model except for the specific value of antenna height. The fading range values used in the desired ILS model to determine $\mathrm{V}_{F}(\mathrm{p}, \theta)$ were also used in the VOR model.

Two $L_{m}$-versus-distance curves were calculated for each aircraft altitude within the horizon. One curve was used for reflections from the counterpoise, where applicable, and the other for reflections from the ground. Both curves were blended in the region where the reflection point was close to the edge of the counterpoise. In order to facilitate this blending, the curves were calculated so that they extended beyond their region of validity.

For reflections from the counterpoise, calculated for elevation angles greater than 5 degrees, the effective earth radius was increased by the height of the counterpoise above ground so that a sphere through the level of the counterpoise became the reflecting surface with a reflection coefficient of -0.9 and the antenna was assumed to be an Alford loop 4 feet above this surface. The aircraft altitude was also adjusted to compensate for the counterpoise height. In these calculations $d_{1}$ 
was very much smaller than $\mathrm{d}_{2}$ and the following two approximations were used to simplify the calculations:

$$
\begin{gathered}
r_{1} \cong h_{1} / \sin \psi \\
\theta_{1} \cong\left(r_{1} \cos \psi\right) / a .
\end{gathered}
$$

Beyond the region where reflection from the counterpoise was important $L_{m}$ was calculated using the methods outlined at the beginning of this section. The antenna was assumed to be an Alford loop located 16 feet above the ground. 


\section{APPENDIX B}

\section{Computation Techniques}

Calculations necessary to produce all desired distributions of transmission loss values or power levels as well as the processes involving the combination of various distributions were so numerous and complex that the use of a large electronic computer was mandatory.

The calculation of transmission loss values, $L_{m}$, was accomplished by modifying existing programs to include the effect of the transmitting antenna only as a function of distance and aircraft haight. The resulting propagation curves were reduced to a set of tables for each aircraft altitude that included $L_{m}$ information for each of the three propagation models discussed in Appendix A. Additional tables for distribution functions of short-term variability and aircraft antenna power gain ratios were developed. This information was then used in the Interference Prediction Program to generate tables of interference ratios for various values of time availability as a function of interference type, station separation and aircraft location. Values of normalized $D / U(95)$ plotted in Section 5 were extracted from these tables.

\section{B. 1 Interference Prediction Program}

The Interference Prediction Program consisted primarily of a series of loops by which the calculations are sequenced and systematic changes of parameters achieved. Figure 12 is a flow diagram of the program showing the series of loops and the computational sequence.

The primary loop considers different aircraft altitudes. At the start of each pass around the loop a set of $\mathrm{L}_{\mathrm{m}}$ tables (as explained above) for a particular height is read in. This loop continues until the supply of tables is exhausted. Altitudes of 1,000,6,250, 12,000, and 18,000 feet were used. 


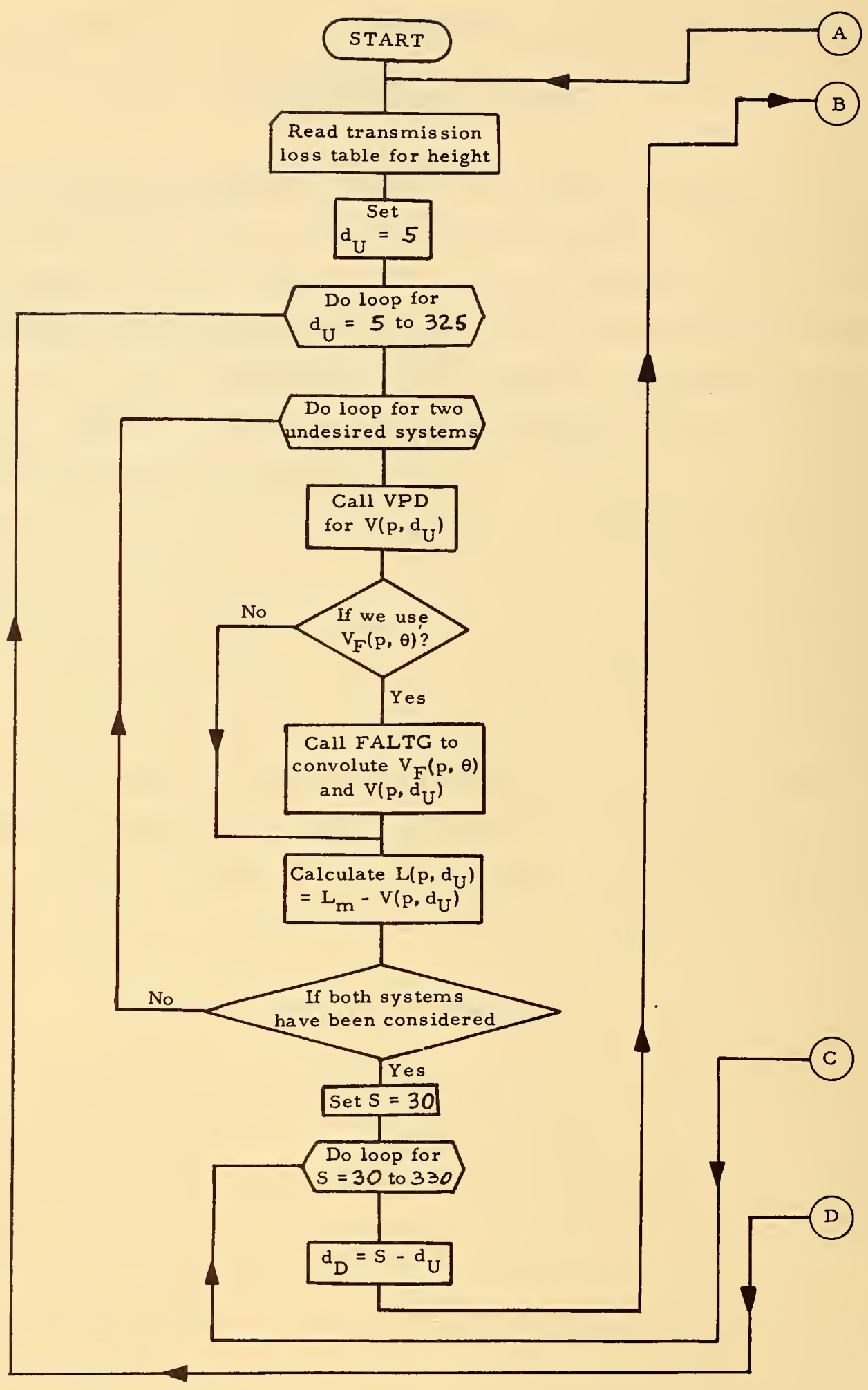




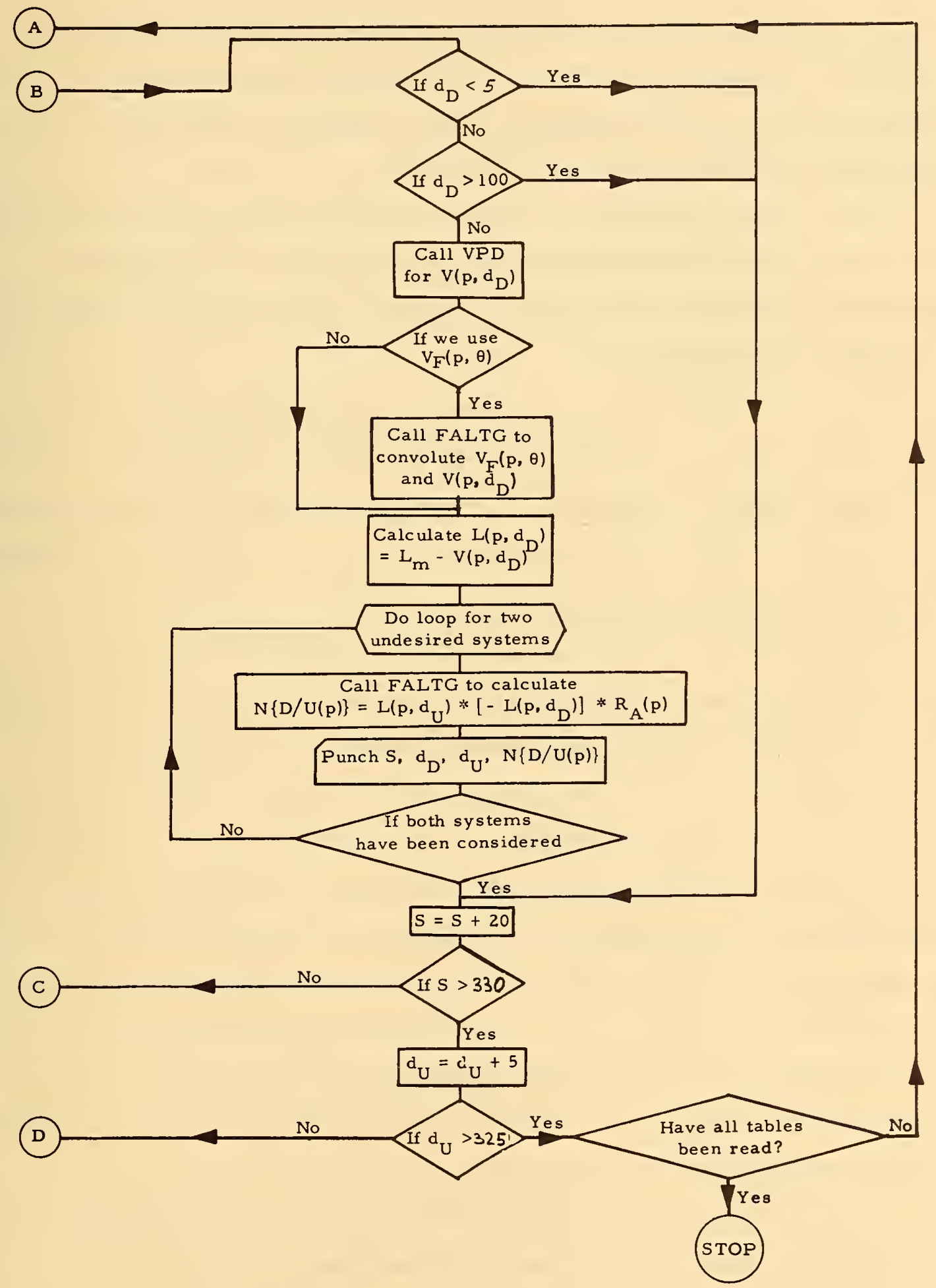

Figure 12. Flow Diagram for Interference Prediction Program 
A secondary loop considers the distance along the great circle path on the ground from the undesired station to the aircraft, $d_{U}$. An initial value of 5 nautical miles is used and this is incremented by 5 miles until 325 nautical miles is reached.

For a given undesired distance an inner loop is used to calculate the time distributions of transmission loss for the two undesired systems. The expression for the cumulative distribution of transmission loss as previously given is

$$
L(p, d)=L_{m}-\left[V(p, d) * V_{F}(p, \theta)\right]
$$

Here the term $V(p, d)$ is the cumulative distribution representing long-term variability of hourly medians. $V_{F}(p, \theta)$ represents the shortterm (within-the-hour) variability.

The symbol * in (27) denotes the statistical convolution of cumulative distributions. Basically, if two variables $x$ and $y$ are statistically independent and given by their cumulative distributions, their statistical convolution is the cumulative distribution of either the variable $\mathrm{z}=\mathrm{x}+\mathrm{y}$, or the variable $\mathrm{z}^{\prime}=\mathrm{x}-\mathrm{y}$, depending on the application of the result, and determined in the machine program by an appropriate input code. The cumulative distribution of $z$ is obtained most simply by selecting $n$ equally spaced percentage values from the individual distributions of both $x$ and $y$, calculating all possible sums $z_{k}=x_{i}+y_{j}$, and forming the cumulative distribution of all values of $z_{k}$ obtained in this manner. Similarly, the cumulative distribution of $z^{\prime}$ is obtained by forming all possible differences $z_{k}{ }^{\prime}=x_{i}-y_{j}$

Successive convolutions are handled by first convoluting two distributions and then using this intermediate result in a convolution with the third individual distribution. The convolution process is cumulative; i.e., the order in which the individual distributions are used does not matter. 
The distributions for the two undesired systems are stored and a new secondary loop which considers the station separation, $S$, is now entered. The initial separation is 30 nautical miles and is incremented by 20 nautical miles until a separation of 330 nautical miles is reached. For a given station separation the desired distance $d_{D}$ is now defined as $d_{D}=S-d_{U}$ and the time distribution of transmission loss for the desired ILS is determined in the same manner as the undesired systems using the median transmission loss value from the appropriate table.

The resultant distribution, $L\left(p, d_{D}\right)$, is then used in conjunction with the $L\left(p, d_{U}\right)$ distributions previously stored to calculate $N\{D / U(p)\}$ for the two desired-undesired station combinations by using the following equation:

$$
N\{D / U(p)\}=L\left(p, d_{U}\right) *\left[-L\left(p, d_{D}\right)\right] * R_{A}(p)
$$

where $R_{A}(p)$, as explained earlier, represents the variability introduced by the aircraft antenna. From these final distributions a number of percentage values between $\mathrm{p}=1 \%$ and $\mathrm{p}=99 \%$ are selected and punched out.

The calculations are primarily handled by three subroutines: FALTG, VPD, and INTERP. This technique enables the program to be more easily changed for other combinations of systems not being considered in this study.

The convolution of distributions is handled by the subroutine FALTG.

The subroutine VPD calculates the predicted long-term variability (or power fading) as a function of the effective distance using the methods developed for a continental climate and presented by Rice, et al. [1965].

With the extensive use of tables, the need to interpolate arises often, and linear interpolation will not always suffice. Therefore, a 
subroutine INTERP was included in the program which calculates the $n^{\text {th }}$ Lagrangian approximation [Lance, 1960], where $n \leq m-1$ with $m$ being the number of entries in the table. The special case $n=1$ results in linear interpolation. As a practical matter, $\mathrm{n}$ is usually required to be less than five. This is necessitated by the fact that Lagrangian interpolation may exhibit large oscillations between tabular entries whenever they do not lie on rather smooth analytic functions.

It should be realized that this discussion is abbreviated, and that the calculation procedure was more involved than indicated. In particular, the method used to extend calculations to a station separation of 20 nautical miles was not discussed. 


\section{REFERENCES}

Barsis, A. P., K. A. Norton, and P. L. Rice (1962), Predicting the performance of tropospheric communication links, singly and in tandem, IRE Trans. on Comm. Systems, CS-10, No. 1, 2-22.

Bean, B. R., and G. D. Thayer (1959), Models of the atmospheric radio refractive index, Proc. IRE 4 7, No. 5, 740.

Civil Aeronautics Administration (1957), Description and theory of the Instrument Landing System, Federal Airways Manual of Operations, IV $-\mathrm{B}-1-4,4$.

Commercial Jetstar Antenna Installation (1959), Report No. ER-3938 (Company Confidential).

Convair 880 Jet-Liner Antennas (1959), Report No. ZN-22-006.

Janes, H. B. (1955), An analysis of within-the-hour fading in 100 - to 1,000-Mc transmissions, J. Res. NBS 54, No. 4, 231-250.

Kerr, D. E. (1964), Propagation of short radio waves, MIT Radiation Laboratory Series 13, 125-130 (Boston Technical Publishers, Inc. , Lexington, Mass.).

Kirby, R. S., J. W. Herbstreit, and K. A. Norton (1952), Service range for air-to-ground and air-to-air communications at frequencies above $50 \mathrm{Mc}$, Proc. IRE 40, No. 5, 525-536.

Lance, G. N. (1960), Numerical methods for high speed computers, 142-144 (Iliffe, London).

McGavin, R. E., and L. J. Maloney (1959), Study at 1, 046 megacycles per second of the reflection coefficient of irregular terrain at grazing angles, J. Res. NBS 63D (Radio Prop.), No. 2, 235-248.

Norton, K. A. (1953), Transmission loss in radio propagation, Proc. IRE 41 , No. 1, 146-152.

Norton, K. A. (1959), System loss in radio-wave propagation, Proc. IRE 47 , No. 9, 1661. 
Norton, K. A., P. L. Rice, and L. E. Vogler (1955), The use of angular distance in estimating transmission loss and fading range for propagation through a turbulent atmosphere over irregular terrain, Proc. IRE 43, No. 10, 1488-1526.

Norton, K. A., L. E. Vogler, W. V. Mansfield, and P. J. Short (1955), The probability distribution of the amplitude of a constant vector plus a Rayleigh-distributed vector, Proc. IRE 43, No. 10, 1354 1361.

Rice, P. L., A. G. Longley, K. A. Norton, and A. P. Barsis (1965), Transmission loss predictions for tropospheric communication circuits, NBS Technical Note 101.

Vogler, L. E. (1961), Smooth earth diffraction calculations for horizontal polarization, J. Res. NBS 65D (Radio Prop.), No. 4, 397-399. 
U.S. DEPARTMENT OF COMMERCE

POSTAGE AND FEES PAID

WASHINGTON, D.C. 20230

OFFICIAL BUSINESS 